\title{
Voice, Identity, and Mathematics: Narratives of Working Class Students
}

\author{
Lynn Liao Hodge (Corresponding author) \\ Department of Theory and Practice in Teacher Education, The University of Tennessee \\ 410 Bailey Education Complex, Volunteer Blvd., Knoxville, TN 37996, USA \\ Tel: 1-865-974-8778Ｅ-mail: lhodge4@utk.edu
}

\author{
Ramona Gartman Harris \\ Department of Mathematics, Gadsden State Community College \\ 1001 George Wallace Dr., Gadsden, AL 35903, USA
}

Tel: 1-256-835-5447Ｅ-mail: rharris@gadsdenstate.edu

Received: September 21, 2015 Accepted: November 3, 2015

Published: December 11, 2015

doi:10.5296/jei.v1i2.8314 URL: http://dx.doi.org/10.5296/jei.v1i2.8314

\begin{abstract}
In this paper, we present an analysis of student interview data focusing on students' ideas about mathematics and their experiences learning mathematics. We draw on the idea of personal identity (Cobb, Gresalfi, \& Hodge, 2009) to capture the differences and similarities in students' views of math and themselves as math learners, although all student participants would be considered members of the same broad, identifiable community. The purpose of our analysis is to contribute to ongoing educational research efforts that challenge processes of essentializing and to use the construct of identity in informing how we design learning experiences and resources for working class students as they learn mathematics.
\end{abstract}

Keywords: Equity, Access, Mathematics, Working class, Low SES

\section{Introduction}

Our purpose in this paper is to unpack the statistics (Magnuson, Meyers, Ruhm, \& Waldfogel, 2004; O'Brien, 2014; Reardon, 2013) and public discourse concerning working class youth and mathematics achievement by revealing the student voices behind the statistics. We 
analyze these voices from the perspective of identity and discuss the strengths and weaknesses of using this lens. In this paper, we present an analysis of student interview data focusing on students' ideas about mathematics and their experiences learning mathematics. We draw on the idea of personal identity (Cobb, Gresalfi, \& Hodge, 2009) to capture the differences and similarities in students' views of mathematics and themselves as mathematics learners, although all student participants would be considered members of the same broad, identifiable community. The purpose of our analysis is twofold: First, we hope to contribute to ongoing educational research efforts that challenge processes of essentializing. These processes include master narratives that society conveys about how certain groups of students are "math people" (Martin, 2004). Second, we seek to use the construct of identity in informing how we design learning experiences and resources for working class students as they learn mathematics.

\section{Why Focus on Class and Mathematics Learning?}

Issues of equity have become increasingly prominent in mathematics education literature within the past twenty-five years. A number of research conferences and published works developed by the National Council of Teachers of Mathematics (NCTM) have focused on issues of equity. A relatively recent issue of the Journal for Mathematics Education (January, 2013) featured a range of articles considering equity and diversity from different perspectives. In addition, popular press has highlighted the educational gap between poor and rich students that begins in kindergarten and continues through high school and adulthood, in spite of efforts of individual students. Although we have made strides in understanding equity in mathematics education, Secada's comments made two decades ago still ring true:

Social class differences are not as problematic in the literature as are racial, ethnic, or other disparities. For example, while the research literature and mathematics education reform documents (National Council of Teachers of Mathematics, 1989, 1991, 2000) at least mention women an minorities, issues of poverty and social class are absent from their discussions. Frankly, the literature does not bristle with the same sense of outrage that the poor do not do as well in mathematics in their middle-class peers as it does with similar findings along other groupings (p, 640).

The more current Common Core State Standards in Mathematics (CCSSM, 2010) have heightened concerns about students from communities that have historically been underserved because the Standards demand higher levels of analysis, problem solving, and communication that many students have not experienced fully perhaps in-school or out-of-school. This situation has developed a sense of urgency to better understand the relationships between socioeconomic status and mathematics learning (Cobb \& Jackson, 2011; Larson, 2012).

Another reason for the analysis presented in this paper is to highlight positive cases of students' learning that give insight into students' perspectives. Gutierrez (2008) argues for analyses that go beyond mere gap gazing at statistics to understanding students' experiences as members of underrepresented communities in mathematics education. These analyses that pay attention to voice and experience emphasize the texture and diversity within groups, 
rather than describing individuals within a group as having one unitary identity. Others have emphasized the need for research that calls attention to students' accounts of their experiences in mathematics (Walker, 2007). Such accounts help us to understand the processes of equity at work, not only the evidence that inequities exist.

A growing number of analyses have focused on identity in order to understand students' and teachers' experiences in teaching and learning mathematics (Boaler, Zevenbergen, \& Dylan, 1999; Martin, 2000). This analysis uses the construct of personal identity to provide a more narrow definition of identity that informs classroom instruction.

\section{Accounting for Underrepresented Students' Difficulties in Mathematics}

A significant body of work has developed in order to explain underrepresented students' difficulties in schooling and academic achievement. We emphasize the main point contributed by scholarship in order to provide background to students' narratives. The theories on which we focus include: Cultural Differences, Reproduction Theory, and Resistance Theory.

\subsection{Differences as They Play Out in the Mathematics Classroom}

In her classic study, Lubienski (1997) offers an illustration of how students' interpretations of activities and ideas in classrooms are related to their membership in home communities. More specifically, Lubienski explores the relationship between socioeconomic class and students' perceptions of statistics. In her study, Lubienski grouped students in her class according to higher socioeconomic status (SES) or lower SES. She remarks on how the two groups showed differences in how the perceived the data collection process. Lubienski indicates that the lower SES students appeared to be unfamiliar with methodological approaches to data collection as compared to higher SES students. Lower students were more likely to use personal stories and common sense when asked to draw conclusions based on data. In contrast, the higher SES students had a tendency to use common in conjunction with the data with which they were presented. The work of Lubienski points out the need for discussions and norms of participation that bring students' ideas and confounding perceptions to the foreground.

One strength of studies that reflect cultural differences is that they draw on students practices in broad and local communities. One of the concerns in drawing on collective aspects is that communities of people are often treated as more homogenous than diverse (Heath, 1983; Lee, 2007). On one hand, drawing on collective aspects is useful in providing instructional resources for the classroom. On the other hand, defining collective aspects of communities runs the risk of essentializing and downplaying diversity within a community. (Calhoun, 1994; Gergen, 1999).

\subsection{Resistance and Identity}

In his book Learning to Labor, Willis (1977) explored the issue of why working class kids get working class jobs. In his study, Willis sought to answer the question of why a group of working class boy would accept such poor treatment from the school. The boys were treated badly by the school in that the manifestations of their working class backgrounds were 
devalued. Willis's central question was: Why did the boys not demand better treatment from the school that would prepare them for better career opportunities than those of their parents? He also sought to understand why this particular group of boys did not accommodate the school's expectations, as many of their working class peers did. Willis did not assume that the boys were passive bearers of their working class culture. He instead sought to understand how the boys were making sense of differences between what was valued within their working class community and what was valued in school. The nature of the explanation that Willis gives to these questions has significance in terms of the idea of resistance.

Willis notes that the "lads" had developed anti-establishment views of the school. They rejected authority and disrupted classes on a regular basis. They also produced an alternative culture including ways of speaking, dressing, and behaving that was very much counter to what the school valued and expected from successful students. These boys drew on aspects of popular culture and the culture of the shopfloor where their parents worked in order to create their counter culture. The counter culture was therefore not a replication of the culture of their home communities, but instead drew on aspects of many communities in which they participated (cf. Eisenhart, 2001). Willis concludes that the boys actively contributed to the reproduction of their relatively low status in society by constructing this local counter culture and fashioning oppositional identities. Willis posits that the boys resistance to the school was not predetermined by their socialization into their working class community.

Willis draws attention to the boys' perceptions of the differences between their working class community and their school. This shift in perspective is significant because Willis focuses on the boys' worlds as they experienced them. He further attempts to use identity as an explanatory construct to understand how conflicts in participation were reconcilable for some and irreconcilable for others. Willis describes another group of boys who come from the same working class community as the lads. They do not replicate the counter culture that the lads had constructed, but engage in a much different culture in which succeeding in school was valued. Willis's study focused on the lads' identities and revealed that they could not reconcile accommodation to the school's expectations with who they were and who they wanted to become. One can see the possibility of students experiencing such conflicts as well.

Our purpose in this article is to present interview data collected from a study that focused on working class students' mathematical experiences. Prior to this discussion, we focus our analysis by explaining the theoretical framework of identity.

\section{Theoretical Framework}

Research in the Sociocultural tradition draws attention to an important aspect of learning that concerns students' development of a sense of who they are in relation to mathematics. From this perspective, students' development of identities is an integral aspect of their engagement in the activities of a community such as the mathematics classroom (Wenger, 1998). Further, students' emerging identities as doers of mathematics are viewed as forms of individuality that are defined with respect to the types of competence that membership in the classroom community entails. Nasir (2002) clarifies that students' developing mathematical understandings and their emerging identities are closely related and co-evolve. In addition, 
she notes that a focus on students' construction of identities as doers of statistics is directly related to several issues that are of immediate concern to most teachers. These include students' interest in mathematics, their persistence and motivation while studying mathematics, and the choices they make about whether to continue to study mathematics and to embark on careers that involve the use of mathematics (cf. Boaler \& Greeno, 2000; Hodge, 2008; Wenger, 1998).

We draw on the idea of personal identity (Cobb, Gresalfi, \& Hodge, 2009) to make the notion of identity more tractable for research. The idea of personal identity provides structure to a narrative approach by emphasizing the 1) normative ways of acting and 2) participants' valuations of these norms from a participant's perspective. In this way, the notion of personal identity informs the design of mathematics classroom learning experiences by documenting the extent in which students identify with the vision of mathematics conveyed through classes and with what obligations they are actually identifying or resisting. Although the data we collected for this study did not focus on a particular classroom setting, the construct of personal identity is useful nonetheless in articulating dimensions of identity that can inform instructional design. These dimensions include students' views of mathematics and what "doing math" means, their views of their own mathematical competence and persistence, and their valuations of their mathematical learning experiences.

\section{The Setting and Participants}

The study was conducted in the Southeast United States. Within the state, there have been multiple efforts to explore the school curricula as a way to raise students' mathematical achievement over the past several years, in particular with the adoption of Common Core State Standards in Mathematics. The focus high school ("Eastside") lies in a city with a population of close to 40,000 and $85 \%$ of the students attending the high school qualify for free or reduced lunch (Alabama State Department of Education, 2010, 2011).

The participants of the study were all twelfth grade students attending Eastside High. Twenty participants, approximately $35 \%$ of the senior class, were asked to participate in interviews about their mathematical experiences, and all twenty individuals agreed. These interviews provided data for a study that examined the experiences of working class students in school mathematics. From this larger collection of data, we selected three individuals in order to discuss how an identity perspective can inform our understanding of working class students and their relationships with mathematics. All three individuals were 19 years old and were selected for this analysis because of the diversity they reflected in academic achievement overall and their relationships with mathematics. In addition, all three individuals offered lengthy responses to interview questions. In addition, we observed these students as they participated in two Algebra II classes and one Technical Math class.

\section{Methodology}

In order to allow the voices of underrepresented groups to be heard, a qualitative design was utilized in this study. Data sources included individual student interviews and field note observations of the classes of which the participants were members. 


\subsection{Interviews}

We initially interviewed twenty high school students who were members of different high school mathematics courses two times during a semester in order to gain an understanding of students' experiences in mathematics. These students were selected in that they reflected diversity in mathematics achievement (reflected in test scores and grades), race and gender, and how they participated in mathematics class (e.g. talkative, ready to give explanations at all times).

The three students on which we focus were selected because they provided diversity in how they regarded mathematics and themselves as mathematics learners. We conjectured that they would provide cases from which to understand how identity can inform an understanding of how and why students form the relationships with math that they do. All three students, and all twenty students in the broader study, qualified for the free and reduced lunch program. In addition, all three students have attended the same high school for the past three years. All interviews were audiotaped and conducted in the school library. The interviews were semi-structured with protocols that were based on prior work (Cobb, Gresalfi, \& Hodge, 2009) with African American students and their experiences with math. Three interviews of approximately one hour during were conducted with all twenty students. Five additional interviews were conducted with each of the three focus students.

\subsection{Data Analysis}

Our goal for this study was to develop a picture of the participants' mathematical experiences. For this analysis, the process used for coding categories was microanalysis, the detailed line-by-line analysis used to generate initial categories (Strauss \& Corbin, 1998). This process was also applied to words, sentences, and paragraphs to discover relationships among concepts and was used for the observational field notes, the audiotaped sessions of the classroom, and the student interviews. During data analysis of this study, the data was organized categorically and chronically, reviewed repeatedly, and continually coded. In doing so, ongoing conjectures were tested and refined in an ongoing manner (Strauss \& Corbin, 1998). Taped interviews were transcribed verbatim and field notes were regularly reviewed for the coding process. Though the process of microanalysis cannot ever be entirely objective because the researcher is reacting to and working with data, the inside knowledge of the researcher can be used to sensitize the researcher to recognize properties and dimensions of emergent concepts (Strauss \& Corbin, 1998).

As the study developed, we progressively refocused to form and shape new research ideas and perspectives, and our ongoing researcher design was continually influenced by events in the field. Therefore we met two times a week to discuss insights thus far and how these insights informed the ongoing research. We made attempts during this process to account for insights. In addition we were careful to consider conflicting finings in order to provide conjectures for these conflicts. Five percent of the interview data were analyzed by another coder and inter-rater reliability was found to be $91 \%$. 


\section{Student Vignettes}

In all three cases, as were the majority of the other twenty students who were interviewed, students attempted to relate their math classes and what they learned in those math classes to their own learning communities. In doing so, many students had difficulties connecting their classroom experiences with their out-of-school experiences. This situated view of learning at the same time calls attention to how students are making sense of the apparent disconnectedness between their participation in the classroom and their experience outside of the classroom.

"Natalie", "Andy", and "Josh" attended school together and had done so since they began in kindergarten. These three students, so similar in demographics, were chose to tell their study because they were very different in their ideas about math, about their own mathematical competence, and about how math is valuable. These three students were representative of some of the important differences within their identifiable working class community.

\subsection{Natalie}

Natalie is a nineteen-year-old Caucasian female and senior at Eastview High School who is outgoing and vivacious. She is a member of the cheerleading squad and a member of several clubs and organizations offered to student during and after regular school hours. Natalie lives with her parents, both of whom work in a manufacturing plant. The family lives on what Natalie refers to as the "East" side of town. She indicates in her interview that residents of the city know this side of town as a place of rough neighborhoods, drug use, and unemployment. It is evident that Natalie does not like the fact that what she termed as "her side of the city" is looked down upon by other citizens. Through her comments, she indicates an awareness of the class distribution in neighborhoods all over the city. Even though the family itself is working class, in Natalie's home learning community, her family is known as having "good jobs" and "having money". As an only child, Natalie is pampered by her parents and her grandfather who lives nearby. She has grown up with a "privileged" attitude because she typically gets what she wants. Her friends know Natalie as a "mall rat", she can always be found shopping at the mall and then wearing her stylish finds to school to show her friends. She is the envy of many of those friends not only for her trendy clothing but because she also has a nice car, which was given to her by her grandfather. For all purposes, Natalie looks the part of any typical teenager.

Natalie enters one of the initial interviews having recently completed her Technical Math class. By her senior year, Natalie has already completed the algebra and geometry requirements for graduation. She requires one more math credit to complete the math requirements for graduation in the state. As she indicates, this is her only reason for taking the Technical Math class, as is the case for many of her senior peers at Eastside High School. Natalie has completed the required Algebra and Geometry classes with the minimum " $D$ " academic grade. She admits that she only applied herself enough to pass the classes because she sees no value in higher-level mathematics. The semester in which the interviews were conducted she was making "B's" in the Technical Math class because she enjoys the practicality of the class. Natalie proclaims that she still hates mathematics in general. 


\subsection{Andy}

Andy is a self assured and somewhat arrogant young man with ideas and opinions that are often the cause of ridicule from other students. Outwardly this does not seem to annoy him. He feels that he knows what he wants and others' opinions are of no consequence. Andy's grades in Algebra II reflect A's and B's, and he considers math to be his favorite subject, noting that it is just a "logical process of calculating numbers". He has no patience with classmates who are experiencing problems understanding the concepts addressed in the course. Andy can quickly visualize the logic in the steps of the process involving any mathematical problem when there is a template of procedures provided by the teacher. Problem that require more problem solving and creativity are problematic for him until he can find textbook clues that offers some kind of road map. Andy admits that he does not like "word problems". However, he had managed to keep his academic grades in Algebra I, Geometry, and Algebra II in the low "A's overall".

Andy's home life is not as idealistic as Natalie viewed hers to be. He lives with his father and stepmother on the east side of town in a neighborhood filled with old home that have not been well maintained with abandoned cars and appliances lining the streets and driveways. He admits that he and his family are poor, yet he is quick to defend their way of living by stressing that he and his family are "hard working" and have paid for what they have, not living "off the government". Yet, Andy has dreams of having the financial security of escaping the humiliation he conveys of living in a poor community. Andy does not seem to have close relationships with either one of his parents. He has not seen his mother in several years and does not appear to speak with her often.

\subsection{Joshua}

Joshua is a quiet young man with an infectious smile and an easy-going manner about him. $\mathrm{He}$ is an African American male who has been the starting quarterback fo the Eastside High School team. He has served as vice-present of the Student Government Association and is active in his church as well as several charitable organizations and clubs. Joshua is enrolled in Algebra II and looking forward to a scholarship to attend a large university in the state. $\mathrm{H}$ has sent several applications to different universities in the state and several, in turn, have contacted him. His smile is charismatic when saying he was waiting for the "best" to contact him.

Joshua has always made average grades in his math classes and professes that it has been "hard work" for him. When group work is part of class, he is usually the individual to whom students look for leadership. He generally reasons out loud with his group and shares his thinking with and elicits ideas from others. Joshua puts aside his athletic persona when he enters the classroom and takes his assignments seriously, reminding his classmates that they have a "job" to do and that "playing" can come later.

His mother, a hardworking single parent by his accounts, raises Joshua. According to Joshua, she had always found the time, between working and caring for Joshua's younger brother, to actively participate in the things that matter in his life. He conveys that she made the posters 
Joshua needed when running for student government and personally placed them strategically around the school. She has also attended all of her son's football games, proudly sporting a replica of her son's football jersey.

The family lives in a modest house located in a neighborhood on the east side of town. The houses in their neighborhood are older yet neatly maintained, as indicated by Joshua. Joshua's family, along with several of the residents of this street, have lived in the same house all of their lives. Some of the current owners are second-generation homeowners of the house in which they were raised.

\section{Insights Gained: Analysis and Interpretation}

We delineate students' personal identities in relation to mathematics by organizing our findings along the following dimensions: Views of Mathematics, Views of Mathematical Competence, and Students' Valuations of Mathematics.

\subsection{View of Mathematics}

Natalie's perceptions of math content derive from prior experiences. In her interviews, she indicated that math content has little or no relationship with who she is and who she wanted to become. She continued to emphasize that the content of mathematics is nonsense and that "formulas and stuff" have nothing to do with her real world. Natalie resisted the approach of following procedures that was emphasized in her math classes in high school. She would "just get by" in her math classes because she "does not like to be told what to do" and "only following what someone has said". She describes her current math class in the following exchange:

I: Let's talk about your math class, Natalie. Do you like your math class?

N: This class seems easier than the other ones I've taken, but I don't like math. I never have. Well, since middle school I never have. Some of those other classes I had to take, like Algebra, I was lost in the woods. This stuff (The Technical Math class content) is stuff you are going to use, not like that other stuff we've had. Like I want those application problems instead of just formulas and stuff that I'm not going to use.

I: What about something that stands out in your math class? Has something you have gone over in class really stood out?

$\mathrm{N}$ : Well, I think the best thing is learning that I was doing those percentages. Wrong. Now when I go to a store to shop, I don't think that everything is on sale for the same price...that it depends on what it originally costs.

I: Does math relate to anything you are doing in your other classes? Or does anything you are doing in your other classes? Or does anything you are doing in your other classes relate to math?

$\mathrm{N}$ : No, not really.

Researchers have suggested that students are unable to use school-learned methods and rules 
in a variety of contexts because they do not fully understand them (Boaler, 1998; Nasir, 2002; Schoenfeld, 1988). Natalie viewed math as consisting of computational skills only. However, she still experienced limited use of mathematical skills in non-school situations, with the exception of percentages that she mentioned.

Andy's comments indicate that he finds comfort in the logical, procedural process of finding the one unmistakable solution to the problems. Andy describe that he has no difficulty with the formulas and properties of algebra, such as "solve for $\mathrm{x}$ ". He recognizes the context of the procedure and quickly went about applying properties to systemically find the solution. However, the situation became problematic with word problems where he had to analyze the problem, decide what operations were needed, and set up the equation to solve the problem. Andy exhibits an inert procedural (Bransford, Schwartz, \& Sears; Schoenfeld, 1985) knowledge that was of limited use because he depended on textbook examples that were followed by a demonstration, a procedure, or method where he was not left with the decision of which method to use (Boaler, 1998).

I: Andy, tell me about your math class. Do you like it?

A: I think it is one of the more important subjects really that you can get into. Math is simple, more straightforward than some of my other classes. I'm a numbers person.

I: A numbers person? How are you a numbers person?

A: Well, if you plug a number into an equation and it's not true, then it's not in the equation. It's just very logical.

I: Does anything you do in math relate to any of your other classes or does anything you do in your other classes relate to math?

A: Uh... there might be some classes that have something to do with math, but I can't think of any. What we do in math is pure fact. This number times this number, every time, same thing with division, or adding, or subtracting. My English class sure doesn't have anything to do with math. All we do in there is read... and write papers about what we read. I hate it. But maybe in science, maybe anatomy has some math in it.

It seems that Andy has a positive affiliation with mathematics since he admitted that math was his favorite subject. He enjoyed the "logic" of solving problems, and made above average scores on achievement tests. However, Andy's perceptions of math are one-dimensional. He does not think of math as employing problem solving skills, but only as using computational skills. He becomes frustrated and easily distracted when tackling problems in which he was not provided a template for steps and procedures.

Joshua comments that he likes "what we do in math" He does not look at mathematical content in the way that Natalie and Andy did, that it is solely a procedural process for achieving a particular solution. His comments indicate that he understands the content to be a means of gaining access to experiences (D'Amato, 1986) and he works hard to meet his challenges. Joshua enjoys school in general and comments that math is "like solving a puzzle". 
I: Do you think that anything you do in math class is related to any of your other classes?

J: Sure. I think the problem solving that we learn in math helps us in all our classes. A lot of people think that math is just solving problems or plugging into a formula. But I believe that math helps us think. Like, sometimes you're not going to automatically know what to do in another class or a situation outside of class, but if you just sit down and think about it, then sometimes the way to figure it out will come to you.

I: Do you like math, Joshua?

J: I like what we do in there. Like the word problems, everybody else hates them, but I like trying to figure them out. It's like a puzzle. The things you need are in the problem, but it's up to you to figure out where they are supposed to go. It's really tight how those formulas and algebra properties work. Man, those people who thought up all those things must have really been smart.

Joshua appears to be a conscientious student who puts forth a great deal of effort in all his classes. There are circumstances in his family community that prohibited the reconciliation of his core identity (Gee, 1999) and his mathematics identity. He has dreams of going to college to become an elementary school teacher, yet his athletic ability has been the focus of family and peers in his school and home communities. Joshua envisions this ability as a vehicle to future success, including attending college.

\subsection{Views of Mathematical Competence}

Natalie's comments indicate that she likes the Technical Math class in which she is enrolled this semester. She does not like to be told what to do and when to do it. Her comments convey no relationship between being able to do math and who she perceives herself to be at this point in her life (and whom she perceives herself as becoming). This is evidenced in her tendency of "giving up" on problems she does not understand.

I: Natalie, think of a line where you have your favorite class on one end and your least favorite class on the other. Where would math fall on that line?

N: Math is last! History is first.

I: Do you have any trouble working on homework and problems in class?

$\mathrm{N}$ : Well, I work harder now than I used to, but the class is pretty easy. I understand it a lot better than the other math classes I had to take before.

I: If you were working on a problem and you couldn't figure out how to solve it, what would you do?

$\mathrm{N}$ : I try to keep doing it until I can figure it out. But if I work it and work it and still can't figure it out, I give up.

I: What do you think it takes to be successful in math?

N: Learning something that's going to get your attention, first of all. Something that you 
really are going to need. Or are you just sitting there listening to something you're never going to use.

Boaler's (1998) study discusses how students in traditional classrooms feel the need to remember the rules and procedures of problem solving, without trying to think about what to do. Students who are never encouraged to discuss the rules and methods or to think about why they may be useful in some situations and not in others, have problems deciding when circumstances are mathematically similar. Questions that do not require an obvious use of a rule or formula cause Natalie to become confused and frustrated.

Andy notes that he understands math completely and that doing math is nothing more than applying the right formula to solve a problem. His comments reflect a confidence in his abilities "to do" mathematics. In addition, he comments that he likes to exhibit his confidence by being the first one to answer a question presented in class. However, his confidence can be viewed as dependent upon a very systematic arithmetical process of calculation.

I: If you get stuck on a problem, what would you do?

A: If I get stuck on something I try to look at what it is that I did before that got me to this point. Usually, if you are stuck it means you've done something wrong previously to this point. So I back up. Sometimes I evenstart all the way over at square one.

I: Think of a line that has your favorite subject on one end and your least favorite subject on the other. Where would you put math on that line?

A: It's probably gonna be top three. I like working problems. I don't like psychology though because it's all about perception.

I: Do you think you are a good math student?

A: Pretty much. In comparison to some of the other students I think I am. I get things done as quickly as I possibly can. And do it in the right manner.

Andy goes through the motions of looking like "a good math student" and appears to regard himself as quite a solid math student. Andy shares the same pragmatic orientation on mathematics as Natalie does. Math must meet the requirements of practicality, must be able to produce a means to an end, and must enable him to advance financially. Andy protests that he is a "numbers person", nevertheless, he admits that he only solves math problems when a template provides guidance to the problem solving process. Andy comments that he does not intend to take any high-level mathematics when he enters college.

Joshua does not trust himself to arrive at the right answer when solving problems. When taking tests, he often second-guesses his answers and becomes easily frustrated. He admits that math is a difficult subject for him, requiring him to study more. Recently, he has experienced the pressure of obtaining an athletic scholarship to pay for college. He uses most of his free time to practice football skills because these, he notes, will make it possible for him to attend college.

I: How would you compare math to other subjects? 


\section{Macrothink}

J: It's a lot harder for me. I have to study a lot harder. I have to take my time with it to understand.

I: If you were working on a problem and you couldn't think of how to solve it, what would you do?

$\mathrm{J}$ : I usually try to work backwards. I get the answer from the back of the book and try to figure out how they got the answer. But on tests, if it's multiple choice, then I work through the problem and if I don't get any of the options, I know I'm totally off. If it's not a multiple-choice test, I just usually take longer. Sometimes, I get frustrated when I can't figure out what to do to get the answer. But then the teacher told us to skip it and come back later. That really helps. When I'm at home working on homework, then I just get up and walk around awhile then come back. I can just about always figure it out then.

I: So, Joshua, describe yourself as a math student.

$\mathrm{J}$ : Oh, man! (laughs) I'm not nearly the math student I want to be. I don't try as hard as I could, I guess. But sports have always been a big part of my life and they take a lot of time, so sometimes that hurts my grades. I try really hard in math and I make okay grades. I just wish they (the grades) were better.

I: So what do you think it takes to be successful in math?

$\mathrm{J}$ : Being able to work the problems through and understanding it. Because you can work a problem and still not understand it. You can follow the steps and know it that day, and then when the test comes, not know it.

Joshua applied himself in his coursework. He considered mathematics to be an important subject with many practical and problem solving skills made available to him. He believed that his math achievement level was not the level it could and should be; however, he felt he must attend to immediate goals first in order for academics to become a permanent asset of his life trajectory.

\subsection{Valuations of Mathematics}

Natalie commented that understanding mathematics is valuable in a practical way. Her sense of value involves paying "bills", buying food and clothing, paying for cars, and understanding one's paycheck. The value that math holds involves completing the four course credit requirements for high school graduation, as Natalie indicates. In this sense, math has instrumental value (D'Amato, 1992) in that it makes future educational and life opportunities accessible.

I: Do you think that math is valuable?

$\mathrm{N}$ : Oh, yes. Not just to graduate and go to college but you need it in just about everything that you do.

I: Who uses math in their lives?

N: Everyone. You got to know that people aren't ripping you off when you buy something. 
You got to pay bills, buy gas. Everybody uses math.

I: So do you think that you will have to use math in the career you choose to go into?

N: I don't think so. I want to be a social worker. I don't think they use math.

Andy's comments indicate a sense of value that is similar to Natalie's initial comments about high school graduation requirements. He has completed the requirements for high school graduation, and he sees this accomplishment as the first step toward his primary goal of having a secure financial future. He observes that math has practical use in his everyday life, that he requires an understanding of mathematics to be successful in his career preparation, and that he will use math as a part of his career.

I: Do you use math outside of school?

A: Every single time I fill my bike up I hit the trip gauge because I want to know exactly how my mileage goes.

I: What do you think it takes to be successful in math?

A: I think the most, the easiest thing to make it to where math is simple, is just to look at it in a logical manner. If people try to look at it as just numbers and formulas and difficulty, it's difficult. If you look at it as serving a purpose, you know as saying this number represents something and it does, all numbers are gonna eventually represent something.

I: Do you think that you will use math in your future career?

A: Yes, right now I want to go into nursing and you have to be good in math to $b$ able to take some of those classes, like dosages of medicine. You have to get those right or you could end up hurting somebody, or even killing them.

Although he seems convinced that math is important and valuable, Andy describes math as having a very limited importance. From his interviews, math has to do with measuring, literally, and any experience having to do with performing calculations.

Joshua is a hard working student who also acknowledges the importance of learning math for graduation requirements. However, Joshua's comments reflect his dreams of going to college on an athletic scholarship, in contrast to the practical motivation indicated in Natalie's comments, or the desire for social mobility, as stated by Andy. Joshua's long-term wishes involves becoming an elementary teacher in order for him to "give back" to his home community.

I: Do you think that math is valuable?

$\mathrm{J}$ : Sure it is. You have to have it to graduate, you're gonna have to take it if you're going to college, and you'll more than likely use it in whatever job you go into. As the three students' comments reflect, math can take on value in different ways for different students. The value that students come to place on math derives from their home and family communities, school learning communities, and their reflections on their learning experiences. 


\section{Summary}

The three students that form the basis of this analysis shared comments that presented different mathematical identities, although all students are part of the same broader community of working class students. In this analysis, Natalie viewed school mathematics in a relatively negative light, only enrolling in math courses that she is required to take. She did not the relevance of mathematics to her life in terms of shopping. Her view of mathematics provided a little substantial connection to her every day life. Andy's responses highlighted a procedural view of mathematics while noting that mathematics is relevant to his long terms goals of working in the health profession. He noted the instrumental value of mathematics in helping him to obtain the educational and work opportunities he hoped to attain. He seemed to excel in the computational aspect of mathematics. Joshua offered the broadest view of mathematics extending beyond procedures and computation to include inquiry and problem solving. He enjoyed and valued the "thinking" aspect of mathematics, but seemed to convey a high level of motivation in all aspects of his life.

\section{Discussion and Conclusion}

In this article, we have examined three students' personal identities in order to show how individuals' relationships with mathematics are complex and cannot be attributed solely to the identifiable group classifications to which students are assigned. The diversity in student stories challenges grand narratives that describe group members as homogeneous and failing in mathematics. A number of implications can be further gleaned from the analysis.

\subsection{The Nature of Students'Identities}

The three students in this study provided comments that conveyed their views of mathematics and views of their own mathematical competence. Natalie's comments indicated narrow views of mathematics that focused on arithmetic, rather than logic or thinking. She describes how she becomes frustrated when tackling problems that she considers too difficult, becoming confused by some of the steps or procedures. Andy has a view of mathematics as applying procedures and formulas. With this perspective, he describes himself as a "good math student". Joshua's comments convey an interest in learning math while acknowledging the instrumental value of mathematics to his future plans. All three students can be described as having some kind of relationship with mathematics. Relationships with content and learning are complex, particularly in how ideas and competencies can come to have value for students. Understanding the kinds of relationships is important is we are to understand how particular people become "math people" who believe that mathematics is important and that they "can do" mathematics.

\subsection{Investigating Identity through Narrative and Observation}

The construct of personal identity focuses attention on understanding both how students regard mathematics and what they consider mathematics to be. In this study, data were collected about students' overall experiences in mathematics and they made decisions about what to glean from their K-12 mathematics education. Complementing this perspective with observations about students' learning experiences would be helpful in understanding the 
instructional setting and the normative practices that come to define specific situations of mathematical learning. This coordination of personal identity and normative identity is helpful in identifying opportunities for access (Greeno \& Hall, 1997; Gresalfi, Martin, Hand, $\&$ Greeno, 2008) and how students participate and regard such practices.

\subsection{Implications for Practice}

The findings point out a critical implication for teaching and learning mathematics with consideration of working class students. Relatively recently, a number of articles published in popular press have highlighted how challenging it is for working class students, no matter how talented and prepared, to move up the corporate ladder in the United States (O'Brien, 2014; Reeves, 2013). These articles highlight the phenomenon of opportunity hoarding. Sociologist, Charles (1998), defines "opportunity hoarding" as the process in which affluent students, even those who are ill-prepared and unskilled, are able to stay at the top of the educational and professional ladder, because of their families' economic status. These economically affluent students win the majority of key life opportunities, leaving limited space on the corporate ladder to their counterparts of lower economic classes. We can zoom in on this process potentially at work at the level of the mathematics classroom as we consider the findings of this study. One wonders how Joshua developed such engaged identities and the opportunities that were part of this process. This raises several important questions: What kinds of opportunities are afforded students to develop engaged mathematics identities? What are the opportunities that need to be created (and experienced) for students to develop engaged views of mathematics like those described by Joshua? How do specific classroom practices create access to identities like Joshua's? This last question leads us to consider the implications of the study for mathematics teaching and learning.

We offer two illustrations here of how specific instructional practices create opportunities for learning and identification. First, Jackson, Garrison, Wilson, Gibbons, and Shahan (2013) describe the importance of the introductory discussion that sets up a complex, high cognitive demand mathematics task. In their article, the authors explain how the instructional practice of introducing a task though a whole-class discussion is linked to the opportunities that are created for students to learn mathematics deeply. Further, one can imagine how the instructional practice of coordinating a discussion creates access to relevance, motivation, and the idea of mathematics as a tool, in a given lesson. Second, Thompson, Philip, Thompson, and Boyd (1994) distinguish between calculational and conceptual orientations that can be discerned in teaching mathematics. Calculational discourse focuses on detailing the procedures that are used in solving a given mathematical task while conceptual discourse includes both the procedures and the reasoning behind the procedures. The instructional practice of drawing on both conceptual and calculational discourse creates opportunities for students to make the procedures and the reasons behind the procedures used to solve a problem explicit to the class. This instructional practice provides students access to approaches and tools with which they may be unfamiliar. In addition, such a classroom practice provides scaffolding in supporting students in understanding how to participate in a mathematical discussion. Stepping back from these two illustrations, the challenge for teachers and mathematics educators is to critically examine pedagogical processes that create 
opportunities or limit opportunities (Haberman, 1991) and to design learning situations for working class students that support inquiry, voice, and community and real world connections.

\subsection{Implications for Research}

The findings of this study lead to a number of implications for research in mathematics education. First, the findings point to the importance of understanding students' perspectives and valuations of their mathematical learning. Studies that investigate specific classroom practices that create opportunities to learn and identify with math and students' thoughts and valuations about these practices would contribute to a growing knowledge base about effective practices that support equity in mathematics education. Second, studies that examine students' individual success stories in mathematics and the specific classroom mathematical experiences are needed to further understand working class students' stories and to understand how to support working class students in being successful in and identifying with mathematics in the context of the classroom.

\section{References}

Boaler, J. (2002). The development of disciplinary relationship: Knowledge, practice, and identity in mathematics classrooms. For the Learning of Mathematics, 22, 1.

Boaler, J., \& Greeno, J. (2000). Identity, agency, and knowing in mathematical Worlds. In J. Boaler (Ed.), Multiple perspectives on mathematics teaching and learning (pp. 45-82). Stamford, CT: Ablex.

Bourdieu, P. (1977). Outline of a theory of practice. Cambridge, UK: Cambridge University Press. http://dx.doi.org/10.1017/CBO9780511812507

Calhoun, C. (1994). Social theory and the politics of identity. Oxford, UK: Wiley-Blackwell.

Cobb, G. W. (1997). More literacy is not enough. In L. A. Steen (Ed.), Why numbers count: Quantitative literacy for tomorrow's American (pp. 75-90). New York: College Entrance Examination Board.

Cobb, P., \& Jackson, K. (2011). Assessing the quality of the Common Core State Standards for Mathematics. Educational Researcher, 40(4), 183-185. http://dx.doi.org/10.3102/0013189X11409928

Cobb, P., Gresalfi, M., \& Hodge, L. (2009). An interpretative framework for analyzing the identities that students develop in mathematics classrooms. Journal for Research in Mathematics Education, 40(1), 40-68.

Common Core State Standards Initiative. (2010). Common Core State Standards for Mathematics. Washington, DC: National Governors Association Center for Best Practices and the Council of Chief State School Officers. http://www.corestandards.org/assets/CCSSI_Math\%20Standards.pdf

Eisenhart, M. (2001). Changing conceptions of culture and ethnographic methodology: 
Recent thematic shifts and their implications for research on teaching. In V. Richardson (Ed.), The Handbook of Research on Teaching (4th ed.). Washington, D. C.: American Educational Research Association.

Gergen, K. (2009). An invitation to social construction (2nd ed.). London: Sage.

Giroux, H., Lankshear, C., McLaren, P., \& Peters, M. (1996). Counternarratives: Cultural studies and critical pedagogies in postmodern spaces. New York: Routledge.

Glaser, B. G., \& Strauss, A. L. (1967). The discovery of grounded theory: Strategies for qualitative research. New York: Aldine.

Heath, S. B. (1983). Ways with words: Language, life, and work in communities and classrooms. Cambridge: Cambridge University Press.

Hodge, L. (2008). Student roles and competence in two contrasting elementary classes. Mathematics Education Research Journal, 20(1), 32-50. http://dx.doi.org/10.1007/BF03217468

Jackson, K., Garrison, A., Wilson, J., Gibbons, L., \& Shahan, E. (2013). Exploring relationships between settings up complex tasks and opportunities to learn in concluding whole-class discussions in middle-grades mathematics instruction. Journal for Research in Mathematics Education, 44(4), 646-682. http://dx.doi.org/10.5951/jresematheduc.44.4.0646

Ladson-Billings, G. (1995). Making mathematics meaningful in multicultural contexts. In W. G. Secada, E. Fennema, \& L. B. Adajian (Eds.), New directions for equity in mathematics education (pp. 329-348). New York: Cambridge University Press.

Larson, M. (2012). Will CCSSM matter in ten years? Teaching Children Mathematics, 19(2), 108-115. http://dx.doi.org/10.5951/teacchilmath.19.2.0108

Lee, C. (2007). Culture, literacy, and learning: Taking bloom in the midst of the whirlwind. New York: Teachers' College Press.

Lubienski, S. (2002). Research, reform, and equity in U.S. mathematics education. Mathematical Thinking and Learning, 4(2\&3), 103-125. http://dx.doi.org/10.1207/S15327833MTL04023_2

Magnuson, K. A., Meyers, M., Ruhm, C., \& Waldfogel, J. (2004). Inequality in Preschool Education and School Readiness. American Educational Research Journal, 41(1), 115-157. http://dx.doi.org/10.3102/00028312041001115

Martin, D. B. (2000). Mathematics success and failure among African-American youth. Mahway, NJ: Erlbaum.

Mehan, H. (1996). Constructing school success: The consequences of untracking low achieving students. Cambridge, UK: Cambridge University Press. http://dx.doi.org/10.1017/CBO9781139174664

Moses, R., \& Cobb, C. (2001). Radical equations: Math literacy and civil rights. Boston: 
Beacon Press.

O'Brien, M. (October 18, 2014). Poor kids who do everything right don't do better than rich kids who do everything wrong. The Washington Post (p. 1). Retrieved from http://www.washingtonpost.com

Ogbu, J. U. (1990). Minority education in comparative perspective. Journal of Negro Education, 59(1), 45-57. http://dx.doi.org/10.2307/2295291

Ogbu, J. U. (1992). Adaption to minority status and impact on school success. Theory into Practice, 31(4), 287-295. http://dx.doi.org/10.1080/00405849209543555

Reardon, S. (2013). The widening income achievement gap. Educational Leadership, 70(8), $10-16$.

Reeves, R. (September 1, 2013). The glass-floor problem. New York Times (p. 1). Retrieved from http://www.nytimes.com

Schoenfeld, A. H. (2002). Making mathematics work for all children: Issues of standards, testing, and equity. Educational Researcher, 31(1), 13-25. http://dx.doi.org/10.3102/0013189X031001013

Secada, W. (1995). Social and critical dimensions for equity in mathematics education. In W. G. Secada, E. Fennema, \& L. B. Adajian (Eds.), New directions for equity in mathematics education (pp. 126-145). New York: Cambridge University Press.

Strauss, A. L. (1991). Qualitative analysis for social scientists. Cambridge, England: Cambridge University Press.

Thompson, A. G., Philipp, R. A., Thompson, P. W., \& Boyd, B. A. (1994). Calculational and conceptual orientations in teaching mathematics. In D. B. Aichele \& A. F. Coxford (Eds.), Professional development for teachers of mathematics (pp. 79-92). Reston, VA: National Council of Teachers of Mathematics.

Tilly, C. (1998). How to Hoard Opportunities. In C. Tilly (Ed.), Durable inequality (pp. 147-169). Los Angeles, CA: University of California Press.

Wenger, E. (1998). Communities of Practice. New York: Cambridge University Press. http://dx.doi.org/10.1017/CBO9780511803932

Willis, P. (1977). Learning to labor: How working class kids get working class jobs. New York: Columbia University Press.

Yackel, E., \& Cobb, P. (1996). Sociomathematical norms, argumentation, and autonomy in the mathematics classroom. Journal for Research in Mathematics Education, 27, 458-477. http://dx.doi.org/10.2307/749877 


\section{Copyright Disclaimer}

Copyright for this article is retained by the author(s), with first publication rights granted to the journal.

This is an open-access article distributed under the terms and conditions of the Creative Commons Attribution license (http://creativecommons.org/licenses/by/3.0/). 